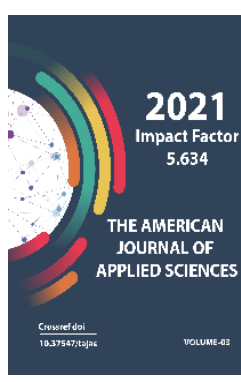

Journal Website: http://usajournalshub.c om/index,php/tajas

Copyright: Original content from this work may be used under the terms of the creative commons attributes 4.0 licence.

\section{Research Of Pentosal Hydrolysis Products Of Plant Waste}

\author{
Roziya Mamadalievna Nazirtashova \\ Assistant Of The Department Of "Chemistry And Biology", Fergana Medical Institute Of Public \\ Health, Uzbekistan \\ Shahobiddin Mirzaraimovich Kirgizov \\ PhD, Acting Professor Of The Department Of Chemistry, Andijan State University, Uzbekistan
}

\title{
ABSTRACT
}

Due to the depletion of fossil reserves of organic raw materials, serious attention is paid to the issues of chemical and biochemical processing of plant raw materials biomass (phytomass) - timber and agricultural plants around the world. This article examines the products of hydrolysis of plant wastes, their physicochemical properties, their importance in industry and the national economy.

\section{KEYWORDS}

Pentose hydrolysis products, catalyst, sulfuric acid, superphosphate, ammonium chloride, furfural, furfuryl alcohol.

\section{INTRODUCTION}

Unlike the source of fossil organic matter, phytomass reserves are renewed annually as a result of plant activity. Every year on our planet 200 billion. tons of cellulose-bearing plant biomass is formed. Cellulose biosynthesis is the largest-scale synthesis of antiquity, present and future. [1] Wood, agricultural crops and coal have been the main forms of organic raw materials for the last 100 years. Worldwide, oil reserves on the planet have been found to be approximately equal to timber reserves, but oil resources are declining rapidly, while timber 
reserves are increasing as a result of the natural growth process of plants. A significant increase in timber resource raw materials will increase the productivity of the required timber products. In the near future, the transition from petrochemical production to chemical and biochemical processing of wood and other forms of plant raw materials is expected.

The processing of biomass of plant raw materials is mainly based on the joint performance of chemical and biochemical processes.

Biotechnology is generally understood as the biochemical synthesis of valuable substances in industry and the processing of biologically derived products. The basis of modern biotechnology is the microbiological industry, which includes hydrolyzed production, which is the basis of production. These productions are based on the hydrolytic decomposition reaction of the glycoside bond of polysaccharides of the biomass of woody plant raw material. In this case, monosaccharides are formed as the main products of the reaction, which are subjected to further biochemical or chemical processing, or are included in the product.

\section{THE MAIN FINDINGS AND RESULTS}

Hydrolysis of plant raw materials is one of the relatively promising methods of chemical processing of wood. This is because when used in conjunction with biotechnological processes, it allows the production of feed and food products, biologically active drugs, monomers and synthetic resins, fuels for internal combustion engines and various other products used for technical purposes [2]. Hydrolysis of plant waste is a non-food plant raw materials (wood waste, cotton husk, sunflower husk and similar) interaction of polysaccharides with water in the presence of catalytic-mineral acids. Primary plant raw materials are usually water-insoluble in the form of cellulose and hemicellulose up to $75 \%$ consists of polysaccharides. As a result of their decomposition, first intermediate compounds are formed, then simple sugar-monoses. In addition to the formation of monosaccharides, their partial decomposition is observed to form furfural, organic acids, humic acid and other substances. The rate of hydrolysis increases with increasing temperature and acid concentration. Hydrolysis of plant wastes is the main hydrolyzed production to obtain important feed, feed and technical products. Under industrial conditions, solutions of hydrolysates-monosaccharides (pentose, hexose, especially glucose), volatile substances (organic acids, alcohols) and solid residue-hydrolysis lignin are formed as products of hydrolysis of plant wastes. The yield of monosaccharides can be up to $90 \%$ higher than that of polysaccharides. The hydrolyzates are subjected to further biochemical or chemical processing, depending on the profile of the hydrolyzed production and the required appearance of the branded products.

Biochemical processing of hydrolysates to obtain protein-vitamin feeds, yeasts is relatively common. One of the most important products of hydrolysis production is ethyl alcohol, which is also obtained by fermentation of hexoses of biochemical path-hydrolysates.

Nutritional glucose and technical xylose are obtained by purification, evaporation and crystallization of hexose and pentose hydrolysates from mineral and organic 
compounds, respectively. In the chemical processing of hydrolysates, polyhydric alcohols are obtained by returning the monosaurs in it: hexoses are formed from hexoses (sorbitol, mannitol, dulcite, etc.), and pentoses are formed from pentites (xylitol, arabite, etc.). Hydrolysis of pentosans in plant products is carried out in the presence of catalysts at 175190 o C at a pressure of 5-10 atm. In this case, the yield is $5-10 \%$ (relative to the obtained raw material). The yield of furfural relative to the total amount of pentosans is $60-65 \%$. The process of separating furfural from hydrolyzate consists of driving it with water vapor, separating the furfural layer from water, and rectifying the raw furfural in a vacuum. This method is one of the most effective methods. In the hydrolysis of pentose products of plants it is possible to produce additional yeast (yeast) and compound feed instead of products that are used as fodder for farm animals. The lignin formed without the use of twigs in horticulture as firewood can be briquetted as an additional fuel. Glycerin, propylene glycol, and ethylene glycol can be obtained by hydrogenolysis of polyhydric alcohols. Furfural is obtained by dehydrating pentoses. Its output depends on the composition of the raw material and the conditions of hydrolysis and dehydration. The dehydration of hexoses results in the formation of levulinic acid, which is used in a number of syntheses.

Pyrolysis of lignin results in the formation of resin and semi-coke. They are subjected to thermal activation to obtain activated gases and decolorizing coals. Hydrolysis to lignin results in the formation of activated carboncollectivitis when treated with concentrated sulfuric acid. When treated with alkali, lignin dissolves, and then when acid is added, activated lignin, which is a phase filler for synthetic rubber, is released. Hydrolysis lignin is also used as a fuel.

Pentose hydrolysis products. Furfurol, $\mathrm{S}_{5} \mathrm{~N}_{4} \mathrm{O} 2$, molar weight 96.08 - low color in water, soluble in alcohol and ether, colorless liquid with a peculiar odor. Liquidus temperature $-36^{\circ} \mathrm{C}$, boiling point $161-162^{\circ} \mathrm{C} / 760 \mathrm{~mm}, \mathrm{~d} 204=1.1594$, $\mathrm{n} 2 \mathrm{Od}=1.5260$. During storage, it turns dark and slowly resin.

Furfurol is a fragrant liquid typical of fresh rye bread, a product of furan. It is obtained from the boiling of agricultural waste (sunflower stalks, straw, sawdust) as well as wood with sulfuric acid. In this case, hydrolysis of hemicellulose (one of the polysaccharides in the plant cell walls) occurs, the resulting pentoses (mainly xylose) undergo dehydration under the influence of sulfuric acid, which leads to the formation of furfural. Furfural is a hardboiling liquid $\left(161.7^{\circ} \mathrm{C}\right)$ with a density of $1.16 \mathrm{~g} /$ $\mathrm{cm} 3$. It is readily soluble in many polar organic solvents, but its solubility in alkanes is not as significant as in water alone.

Chemical properties. They undergo reactions characteristic of aldehydes. The furan ring of furfural has an aromaticity, so it is somewhat reminiscent of benzaldehyde in its properties. It is characterized by exchange reactions (case 4 with respect to the aldehyde group). Under the influence of alkalis, furfural reacts like Kanzaldehyde with Kannitstsaro. In this case, the salt of furancarboxylic acid and furfuryl are disproportionate to alcohol. It is hydrogenated and reacts more easily than benzene-ring aromatic compounds. The Dils-Alder reaction enters just like the Dians. When heated to $250^{\circ}$ C, furfural is sometimes decomposed into furan and carbon monoxide by explosion. 
When heated in the presence of strong acids, the oxygen in the furan ring attaches to the proton, the aromaticity is disrupted, resulting in the polymerization of furfural.

Application. Furfural is used in petrochemical organizations as a solvent for the extraction of diene from a hydrocarbon mixture (used in the synthetic rubber industry). Furfural is used in industry as a raw material for the production of furfural-acetone monomers, difurfurilidenacetone, furfuryl alcohol, tetrahydrofurfuryl alcohol. These monomers are used to obtain acids, alkalis, oxidants, reducing agents, and oil-resistant monomers.

Furfural and furfuril alcohol can be used together or separately to obtain solid resins (resins) by reaction with phenol, acetone or in the presence of urea. Such resins are used in the manufacture of fiberglass, some parts of aircraft and automotive brake pads. Furan is obtained from furfural, which in turn is used to obtain the famous solvent - tetrahydrofuran. It also serves as a starting material for the production of antimicrobial drugs in the nitrofuran group, such as furatsilin, furazolidone, furadonin, furazoline, furagin.

Furfuryl alcohol S5N602, with a specific odor of 98.05 molar, soluble in water, alcohol and ether, boiling point $68-69^{\circ} \mathrm{C} / 10 \mathrm{~mm}, 170-171^{\circ}$ C / $758 \mathrm{~mm}, \mathrm{~d} 22.74=1.1282$, A colorless liquid with $n 22.7 D=1.4851$ turns light yellow when in air.

Furan S4N4O, molar weight 68.03. It is a colorless liquid insoluble in water, easily soluble in alcohol and ether, with a boiling point of $31-32^{\circ} \mathrm{C} / 760 \mathrm{~mm}, \mathrm{~d} 204=0.9087, \mathrm{n} 2 \mathrm{OD}$ $=1.4220$.
A large group of furan oxob compounds obtained from the condensation of furfural with aliphatic aldehydes and ketones (furfurylidenacetone, furylacrolein, 2-ethyl bfurylacrolein, 5-furylpentadienol, 1-furyl-5oxohexadiene $-1,3^{\circ} \mathrm{C}$, nickel at $170^{\circ} \mathrm{C}$ ) in the liquid phase hydrogenated in a solution of ethyl alcohol at room temperature. The corresponding tetrahydrofuran alcohols were formed with a yield of $76-92 \%$.

Condensation of furfural and furlacrolein with esters of carbonic acids results in the formation of esters of acids exchanged from furfuryl. Ethyl ether of $\beta$-furylacrylic acids from furfural and ethyl acetate; ethyl ester of $\gamma$ furfurylidencrotonic acid from furylacrolein and ethyl acetate; from furfural and malon ether - furfurilidenmalon ether. It is possible to obtain completely non-hydrogenated products by hydrogenation of these compounds in Renee nickel at different temperatures. The ether of $\beta$-furylpropionic acid was converted to $\beta$-furylpropionic acid ether at $110-120^{\circ} C$, and then to $\beta$ tetrahydrofurylpropionic acid ether at continuous hydrogenation at $175^{\circ} \mathrm{C}$ (yield 92\%).

$\gamma$-furfurilidencrotonic acid ether was first hydrogenated in a solution of ethyl alcohol at room temperature and then at $180^{\circ} \mathrm{C}$. As a result of complete hydrogenation, бtetrahydrofuril valeric acid ester was obtained (productivity 90\%) $[3,4,5,6]$.

Hydrogenation of furan compounds in the vapor phase in nickel catalysts leads to the hydrogenolysis of the furan ring to tetrahydrofuran or its ring with the formation of a grouping of alkylcarbonyl or alkylhydroxyl atoms from carbon atoms. The difference in temperature in the hydrogenation of 
The American Journal of Applied sciences

(ISSN - 2689-0992)

Published: April 29, 2021 | Pages: 126-130

2021: 5.634

Doi: https://doi.org/10.37547/tajas/Volume03Issue04-17

OCLC - 1121105553

furfurylidenmalone ether is the same carbetoxy affects group cleavage. Tetrahydrofurylmalon ether (productivity 96\%) is formed at $100-130$ C, tetrahydrofurylpropionic acid ether at $160-175^{\circ}$ c.

A good catalyst is a skeletal $\mathrm{Ni}-\mathrm{A} 1$ catalyst. In the Shuikin and Bunin studies [7], hydrogenation of furan and silvanes in the vapor phase at $100-140^{\circ} \mathrm{C}$ and $120^{\circ} \mathrm{C}$ in a Ni-A1 skeletal catalyst prepared for incomplete leaching of aluminum was studied. At this temperature, the yield of tetrahydrofuran and tetrahydrosilvane is relatively high, but when the temperature rises to $170^{\circ} \mathrm{C}$, furan decomposes into gaseous products. Burnett obtained only $50 \%$ tetrahydrosilvane and a significant amount of hydrogenolysis products - pentanone-2 and pentanol-2 - at a temperature of $200^{\circ} \mathrm{C}$ in a catalyst prepared by the same method ( $68 \%$ aluminum was lost).

Comparative data on the lattice catalyst and temperatures in the hydrogenation of silvan are given by Wilson [8]. Among the studied catalysts - nickel, copper chromite, So-Si and G'e-Si catalysts were relatively active nickel catalysts, in which $100^{\circ} \mathrm{C}$ support tetrahydrosilvane is formed with $86 \%$ yield, and at $185^{\circ} \mathrm{C}$ selective hydrogenolysis results in petanone - 2. $75 \%$ yield is formed. Other catalysts undergo hydrogenolysis of the furan ring with relatively less selectivity and at higher temperatures $\left(340-350^{\circ} \mathrm{C}\right)$. Michromite and So-Si catalysts produce 52 and $60 \%$ pentanone2, respectively, while the G'e-Si catalyst produces about 10\% ketone and mainly tetrahydrosilvane.

\section{CONCLUSION}

In conclusion, it can be said that various monomers, polymers, copolymers, pharmaceuticals, physiologically active substances, various solvents are obtained in the industry on the basis of furfural, which are products of hydrolysis of plant wastes. These products are effectively used in various sectors of the economy. In view of the above, by studying the data on the extraction of substances from various wastes that may be necessary raw materials for the chemical industry, and considering the unique role of plant wastes and biomass as natural sources of organic compounds, We are conducting scientific research in order to ensure the production of products needed in the national economy. Our next articles will provide information about the results obtained.

\section{REFERENCES}

1. Abdullaev Sh. V. "Chemistry of heterocyclic compounds" NamSU. 2020.

2. Internet site "KHIMIK.RU"

3. KA Ubaydullaev, AQ Saidvaliev "Pharmaceutical Chemistry" "Ilm Ziyo" Publishing House, Tashkent, 2016, 216 pages.

4. Goryaev S.S "Synthesis and prevrasheniya b-zameshennyx a-carbonylnyx soedinenii furana. RGU, Rostov-on-Don, 1973.

5. Gusarova $\mathrm{VV}$ "On the action of furfurola on the metabolism of cormorants" VASXNIL, Lelingrad, 1973.

6. Daurenbekov B.D. Hydrogenation of furfurola and furfurilogo alcohol in a solution on a stationary catalyst in the columnar apparatus.IOKE, Alma-Ata, 1971

7. Shuykin N.I, Bunina V.I. JOX, 8,669 (1938).

8. C.L.Wilson. J.Am.Chem.Soc., 70,1313 (1948). 